\title{
The work of the Konrad-Adenauer-Stiftung (KAS) in Northeast Asia
}

\author{
Stefan Samse, Rabea Brauer, Alexander Badenheim, Peter Hefele ${ }^{*}$ (iD and David Merkle
}

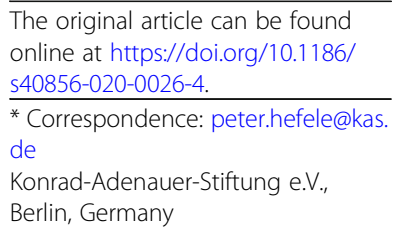

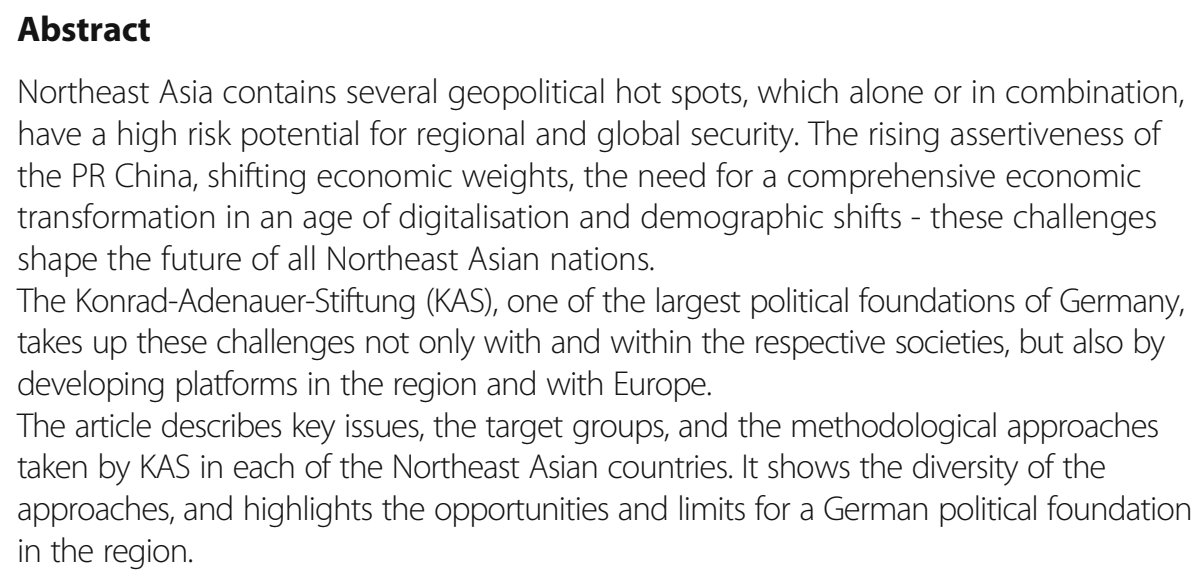

Northeast Asia contains several geopolitical hot spots, which alone or in combination, have a high risk potential for regional and global security. The rising assertiveness of the PR China, shifting economic weights, the need for a comprehensive economic transformation in an age of digitalisation and demographic shifts - these challenges shape the future of all Northeast Asian nations.

The Konrad-Adenauer-Stiftung (KAS), one of the largest political foundations of Germany, takes up these challenges not only with and within the respective societies, but also by developing platforms in the region and with Europe.

The article describes key issues, the target groups, and the methodological approaches taken by KAS in each of the Northeast Asian countries. It shows the diversity of the approaches, and highlights the opportunities and limits for a German political foundation in the region.

Keywords: Northeast Asia, North Korea, South Korea, Japan, PR China, Taiwan, Political Foundation, Security policy, Transition policy, Nongovernmental policy

\section{Introduction}

Besides being one of the most geologically and tectonically active zones on earth, Northeast Asia also has a number of geopolitical hot spots, which, whether viewed alone or in combination, have a high risk potential.

Historical conflicts with roots stretching back to the end of the nineteenth century, or even earlier, have still not been "managed" to this day. Relations between the states and societies of Northeast Asia are marred by distrust, which prevents constructive cooperation in tackling common regional and global challenges.

From a foreign and security policy perspective, the emergence of the People's Republic of China as Northeast Asia's leading economic power and second strongest military power is the key factor in the dramatic shift in the regional and geopolitical tectonics of Northeast Asia. The country is pursuing its territorial objectives with increasing aggressiveness (partly in breach of international rules) and developing its ability to project power beyond its current maritime territory.

Despite being members of several regional alliances, the countries of Northeast Asia still have no effective regional security architecture. This deficit is exacerbated by other trouble spots: the conflict surrounding the nuclearisation of North Korea; and the disputes between Japan and (South) Korea over crimes committed during the Japanese occupation.

(c) The Author(s). 2020 Open Access This article is distributed under the terms of the Creative Commons Attribution 4.0 International License (http://creativecommons.org/licenses/by/4.0/), which permits unrestricted use, distribution, and reproduction in any medium, provided you give appropriate credit to the original author(s) and the source, provide a link to the Creative Commons license, and indicate if changes were made. 
Northeast Asia is becoming increasingly integrated in the economic "axis" of the People's Republic of China. Even the world's third and eleventh largest national economies (Japan and South Korea) now have the closest possible ties with the emerging superpower China. At the same time, however, China uses its economic influence to assert political demands (e.g. in territorial disputes). All three major economies of Northeast Asia are facing similar challenges arising from the need to restructure their economic systems: in the shift to knowledge-based economies, digitalisation and artificial intelligence. At the same time, intra-regional competition grows more intense because future value creation (as is the case in Europe) is sought in identical fields such as in robotics, nanotechnology and biotechnology.

While South Korea and Japan are both fundamentally committed to multilateral and global regulatory systems (e.g. the World Trade Organization), China is working to develop its own alternative regulatory models.

And yet a range of challenges facing Northeast Asian societies are of a similar nature. Demographic change, triggered by low birth rates, the absence of immigration, and a rapidly ageing population, has already become one of the unresolved questions concerning social cohesion and the future of social security systems in China, Japan and South Korea. It is by no means certain whether the simultaneous transition to digitalisation will be able to mitigate (some of) these negative consequences or tend to intensify them further. In either case, these societies are undergoing structural change that has never been seen before, and that is by no means complete.

By running three country projects - in the People's Republic of China (Beijing/Shanghai), Japan (Tokyo) and Korea (Seoul) - and its regional programmes (Social and Economic Governance Programme in Asia (SOPAS)/Tokyo) and Energy Security and Climate Change (RECAP/Hongkong) KAS takes up these challenges - not only with and within the respective societies, but also by developing platforms in the region and beyond. At the same time, they see themselves as seismographs for developments that also affect Europe in a similar way, and that are discussed in bilateral and multilateral forums.

Each of the following sections provides a concise overview of the key issues, the target groups, and the methodological approaches taken. This shows the diversity of the relevant contexts, and highlights the opportunities and limits for a German political foundation in the region of Northeast Asia.

\section{Korea}

The Konrad-Adenauer-Stiftung established its Korea Office as early as 1978, being one of the first of its kind in Asia; ever since then, it has been based in South Korea's capital, Seoul. Initially, the Korea Office addressed issues such as the development of rural areas, the participation of women in society, political education, and the decentralisation and strengthening of civil society.

The large number of former KAS scholarship holders in Korea from that era is remarkable. Many of the 150 or more former KAS scholarship holders have gone on to become leaders in their traditional areas after returning to Korea. In their roles as academics, researchers and policymakers, alumni scholarship holders endeavour to further deepen ties between Germany and Korea. The KAS Korea Office brings together former scholarship holders at an annual meeting, and organises joint conferences on a variety of key topics. 
The KAS has both South Koreans and North Koreans among its former scholarship holders. In early 2000, North Korean journalists were invited to Germany to foster exchange in the field of journalism. Moreover, KAS support enabled several North Korean law students to be trained in Germany. The purpose of these measures is to invite North Koreans to Germany and to show them as much as possible of life's realities outside the closed cosmos of North Korea. The aim is to facilitate long-term cooperation between Germany and North Korea - in an unquestionably difficult context.

In the past 2 years, the KAS Korea Office has conducted several delegation visits to North Korea in a bid to promote bilateral exchange. Delegations have included Bundestag and Landtag members, legal scholars and agricultural experts. These contacts have allowed a degree of trust to be built. KAS has teamed up with German university lecturers to deliver seminars on international law and civil law for law students in North Korea. To follow up these visits to North Korea, German parliamentarians sought to strengthen cooperation in the fields of sport and health. All these activities are attempts to assist North Korea's opening up to the international community.

Besides maintaining limited contacts to North Korea, KAS is particularly viewed as a reliable partner in South Korea. During the difficult phases of inter-Korean relations, there was particularly close consultation with the South Korean government's Unification Ministry. As such, the Korean employee of the KAS Korea Office who accompanied delegation visits to North Korea is one of just a handful of South Korean nationals who have been granted the necessary travel permits for both Koreas.

However, the Konrad-Adenauer-Stiftung is primarily engaged in the south of the Korean peninsula. This is where it implements the vast majority of its projects and educational measures.

The KAS Korea Office has established close cooperative activities and exchange programmes with the Yeouido Institute (YDI), which is considered to be the research institute of the Liberty Korea Party (LKP). Young politicians have been invited to Germany, and German experts have delivered seminars and conferences at the YDI. The KAS Korea Office aims to present and discuss party programmes, election manifestos and strategic issues concerning German election campaigns at the YDI. Mutual understanding is to be enhanced by fostering exchange between parliamentarians and parliamentary staff from both countries.

Issues concerning the rule of law and democracy are another important thematic area. For over 30 years, the KAS Korea Office has teamed up with the Korean Public Law Association to hold symposia on public law. In addition, the KAS Korea Office has been collaborating with the Law School of Korea University on contemporary legal issues for 5 years. The joint events held were on topics such as "judicial independence", the "importance of democracy and constitution" and the "possibilities and limits of constitutional change". More than 400 students take part in conferences each year.

The KAS Korea Office also cooperates closely with one of Korea's most important civil society organisations, the Citizens' Coalition for Economic Justice (CCEJ). The objective in this case is to address the topic of economic inequality. The German social market economy in particular was presented and discussed as an "alternative" economic model. The two organisations' current cooperation theme is the "Fourth Industrial Revolution". Together with its partner organisation, KAS endeavours to bring civil society closer to the change processes that are viewed with deep scepticism by the 
Korean population, reflecting together on the opportunities and challenges surrounding this future model.

Security policy on the Korean peninsula and in the Northeast Asian region is another of the main issues addressed by KAS in Korea. Each year, KAS joins forces with the Research Institute for National Security Affairs (RINSA) - the Korea National Defense University's research institute - to organise a German-Korean conference on security policy and strategic issues. Experts from both countries engage in intensive debate to try to view the other's problems from a new perspective by giving impetus to each other.

The integration of North Korean refugees into South Korean society is another field of activity in which the KAS Korea Office is involved. KAS delivers seminars for teachers in cooperation with Yeomyung School, a special educational institution for North Korean refugees. Reports focus primarily on the German experience after the fall of the Berlin Wall, when education systems from two completely different political systems had to be brought together in Germany.

In the four decades since establishing its Korea Office, KAS has sought to act as a platform for German-Korean exchange in politics, higher education, research and civil society, facilitating a wide range of contacts and bilateral cooperation efforts.

\section{Japan}

As early as in the nineties, KAS appreciated the political and economic importance of Japan for Europe, and was present in Tokyo for a number of years accordingly. In 2011, KAS reopened its office in Japan, partly to underline Germany's solidarity with Japan following the triple disaster in the northeast of the country.

The principles of a free democratic basic order and political notions of order and values are shared by both Germany and Japan. Both nations acknowledge their global responsibility for the peaceful coexistence of free and open societies. However, there is still room for improvement in bilateral relations between them - not only in party political issues, but also in the area of economic policy. The work of KAS focuses on these aspects.

Around the world, the Konrad-Adenauer-Foundation supports the German approach for multilateral cooperation to tackle international crises and challenges - this also holds true in Japan. KAS seeks to enhance the role of Germany and Europe in Japan and the region in the long term. The foundation has initiated regular discussions between Japanese, German and European decision-makers and experts at Track II level. In cooperative activities with government and academic partner institutions, participants are encouraged to exchange views on their understanding of common challenges, define shared solutions and strengthen strategic partnerships.

Another task undertaken by KAS is to identify issues for which Japan has no comprehensive strategy of its own yet (e.g. the integration of foreign labour), needs partners (e.g. new technologies, alternative energies, robotics) or wishes to learn from Germany's experience (e.g. cyber security in the field of enterprises).

By the same token, KAS helps cater to Germany's interests in Japan. To this end, experts exchange ideas on technologies in which Japan is way ahead of us (e.g. hydrogen as a source of energy, drive systems, vertical/techno farming using artificial 
intelligence, and robotics in nursing and medical care and in services). Japan is currently a key driving force in these areas on the global stage.

Japan has a critical role in shaping future economic developments in the region, owing to the Japan-EU Free Trade Agreement (JEFTA) and the Strategic Partnership Agreement (SPA) with the European Union, and the regional free trade agreement CPTPP (which was a replacement for the original Trans-Pacific Partnership (TPP) with the USA). Besides implementing multilateral and bilateral free trade agreements, Japan, which holds the G20 Presidency this year, is setting the standards for a reform of the WTO, data governance, green, and maintenance of the liberal world order. All these undertakings make Japan an ideal location for the work of KAS.

The foundation also addresses social security models with potential for the future, and labour migration issues. The guiding themes for expert discussion arise from the implementation and socio-political shaping of the Industry 4.0 (Germany) and Society 5.0 (Japan) concepts. The themes include technology transfer, digitalisation, the future of work, innovation, and human capital development. These sets of issues are intertwined with the challenges presented by the aforementioned regional free trade agreements, which, when implemented, have a direct impact on how the liberal, rules-based global order is shaped, and on the future of world trade.

Germany has never (as yet) played a significant role for Japan in terms of security policy. It is therefore all the more important that KAS reflects regional developments in Germany and makes them accessible to decision-makers. Foreign policy discourse in Germany is only slowly becoming aware of the Indo-Pacific strategy, initiated by Japan, even though this alliance is, to date, the only response to China's claims to hegemony. The foundation's political assessments of regional developments, whether in the Pacific, the South China Sea or the East China Sea, are essential for not only parliamentarians to understand the threat of security policy conflicts and potential military hostilities.

It is generally important to foster close bilateral exchange between parliamentarians and parliamentarian or friendship groups. This can be achieved by way of the aforementioned topics, delegation visits and the involvement of Japanese parliamentarians or parliamentary staff in the regional activities of KAS (e.g. Konrad Adenauer School for Young Politicians, Election Bridge, the group of foreign policy experts, and digitalisation forums).

There are, of course, areas where Japan and Germany can set standards together. Japan has been a stable, reliable economic and development partner in the region for decades - just like the European Union. Japan and the EU continue to be the most important and biggest donors in the region to Southeast Asia. In recent years, Japan's official development assistance (ODA) exceeded $€ 10$ billion. Both Japan and the EU view development aid not just as an obligation, but as an instrument to keep peace in the region. Japan also attempts to roll back the growing economic influence of China in this way, but is unable to reverse the existing political and economic dependence on China of states such as Cambodia, Laos and Myanmar. KAS is committed to sounding out similarities between Japan's and Germany's development cooperation, hoping to identify potential joint projects in third countries. Both Japan and Germany pursue development objectives in line with the Sustainable Development Goals (SDGs) in all of their partner countries; they act as advocates of the democratic process, speak out for transparency, 
conditionality and sustainability, and help combat corruption. This is primarily where the similarities lie and, especially, the potential for long-term, farsighted cooperation.

\section{The People's Republic of China}

The Konrad-Adenauer-Stiftung has been active in the People's Republic of China since the 1980s. The first office to which a German representative was posted was opened in Beijing in 1996. A second representation followed in Shanghai in 2001. In addition, a regional project addressing the key subject of energy security and climate change in the Asia-Pacific region was launched in 2015, based in Hong Kong.

The work of the project offices in Beijing and Shanghai focuses on strengthening Sino-German understanding and partnership, and on promoting bilateral exchange between China and Germany in the areas of politics, science, business, law and social sciences. KAS also seeks to contribute to the sustained success of China's economic reform process and to the dismantling of regional disparities.

The KAS Beijing Office focuses on promoting policy exchange and on developing and expanding channels and formats of political dialogue. German and European experts from the realms of politics, business and academia are brought together with Chinese party and government representatives at conferences and roundtable discussions, to share ideas about current national, regional and global issues. For this purpose, study programmes are also organised on a regular basis. These programmes give experts in certain policy areas the opportunity to find out about the latest trends and developments in the other country, and to discuss common challenges with local experts.

In the area of political dialogue, KAS organises platforms for young politicians and future leaders in policy consultancy (e.g. think tanks, or government-related institutions) to foster exchange on topics that are important for the future of their generation and generations to come, such as digitalisation, education and demographic challenges.

China's urbanisation process also plays an important role in this context. KAS has been working on this topic since 2013, the year when the Federal Chancellor Angela Merkel and China's Premier Li Keqiang signed the Sino-German Urbanisation Partnership. The aim of KAS' activities in this area is to stimulate a pluralistic debate among local politicians and political advisors on sustainable forms of urbanisation, and to analyse the relevance of German experiences in the field for China.

KAS is also involved in the German-Chinese Rule of Law Dialogue, initiated by the two governments in 2000. Activities in this area currently range from environmental law and civil law, to issues relating to the international settlement of disputes by courts of arbitration. The KAS China offices have already published a number of studies on this matter and undertaken comparisons of German and Chinese law.

Besides legal aspects, another key area of KAS' activities in China is the ecological, financial and technical aspects of climate action and environmental protection. Aspects such as e-mobility and the development of renewable energy are also discussed in this context. The work of KAS in China also focuses on economic issues, such as structural change in the Chinese economy, from an export-dominated model that is environmentally damaging at times, to a sustainable, innovation-driven model. The transformation 
of China's state-owned enterprises, which continue to be very significant for the Chinese economy, also plays an important role in this discussion.

Digitalisation and the implications resulting from it is also incorporated into the work of the KAS China offices, given that it is a key priority of current policy in both countries. Areas such as e-health, e-learning and e-governance and their practical and legal frameworks and development opportunities are therefore examples of important topics in Sino-German discussions. Bilateral relations have always been an essential pillar of KAS' activities in the field of foreign policy with a reference to foreign policy. Germany and China are strategic partners, and the two countries have held regular Sino-German intergovernmental consultations since 2011. Many of the topics discussed in the process are also used as a basis for discussion for KAS-initiated exchange among representatives from think tanks, academics and party politicians. In this context, KAS cooperates with China's key state and non-state think tanks, and draws on its extensive network in Germany to bring together leading experts from both countries.

In the wake of globalisation and China's growing involvement in the world, which goes beyond trade-related matters and the Belt and Road Initiative, the activities of KAS in China also focus on questions about the role of China in the international system, such as in multilateral institutions, as well as on standards for good governance in the global context. Cooperation between Germany and/or the EU and China in third regions such as Africa also plays an increasingly important role.

\section{Taiwan}

The Konrad-Adenauer-Stiftung also has close contacts to Taiwan by cooperating with academic institutions and by maintaining its network of alumni scholarship holders. Taiwan, officially called the Republic of China, has increasingly been on the receiving end of sabre-rattling by the People's Republic of China. As the global influence of the People's Republic of China grows, Beijing's narrative that "Taiwan is an integral part of China" seems to have become widely accepted and the status quo between the two entities faces risks of further imbalances. It is therefore appropriate to support adherence to the integration of Taiwan in international organisations so as to maintain the rules-based international order. Germany, like most other countries, has no official relations with Taiwan. Instead, it has a close and trusting relationship with the 24 million-strong island state at the level of academic exchange, business and culture. Since its first free presidential election in 1996, Taiwan has evolved into a lively democracy, and since then has experienced an orderly, peaceful transfer of political power three times. Throughout Asia, Taiwan advocates a values-based order, and actively shares its experiences from its own dictatorial past and the principles of the rule of law and democracy that it has gained by way of social engagement and political change. Taiwan is Germany's fifth-largest trading partner in Asia, and an important research and development partner, owing to its advanced technological standards in IT and biotechnology. There is also a close alignment with and orientation to the German law, respectively in the civil law and constitutional law, which provides room for close legal exchanges. Pluralism and the culture of participation in Taiwan has resulted in a large number of social innovations and an active role of environmental organisations, offering considerable room for cooperation at the civil society level. 


\section{Abbreviations}

CCEJ: Citizens' Coalition for Economic Justice; CPTPP: Comprehensive and Progressive Agreement for Trans-Pacific Partnership; G20: Group of Twenty; JEFTA: Japan-EU Free Trade Agreement; KAS: Konrad-Adenauer-Stiftung; LKP: Liberty Korea Party; ODA: Official Development Aid; RINSA: Research Institute for National Security Affairs; SDG: Sustainable Development Goals; SOPAS: Soziale Ordnungspolitik in Asien; SPA: Strategic Partnership Agreement; TPP: Trans-Pacific Partnership; WTO: World Trade Organisation; YDI: Yeouido Institute

Acknowledgments

Not applicable.

Authors' contributions

All authors read and approved the final manuscript.

Funding

Not applicable.

Availability of data and materials

Not applicable.

Competing interests

The authors declare that they have no competing interests.

Received: 20 December 2019 Accepted: 20 December 2019

Published online: 31 December 2019

\section{Publisher's Note}

Springer Nature remains neutral with regard to jurisdictional claims in published maps and institutional affiliations.

Submit your manuscript to a SpringerOpen ${ }^{\odot}$ journal and benefit from:

- Convenient online submission

- Rigorous peer review

- Open access: articles freely available online

- High visibility within the field

- Retaining the copyright to your article

Submit your next manuscript at $>$ springeropen.com 